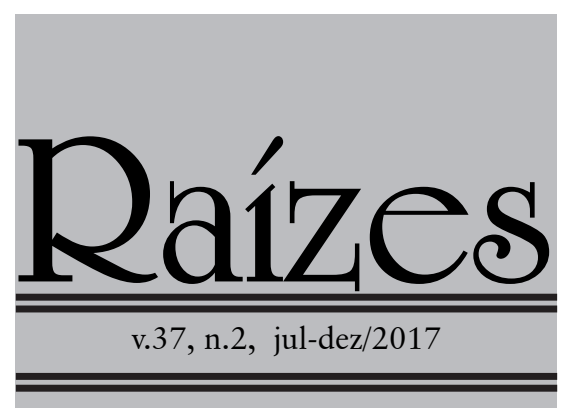

\title{
CONCEPÇÕES DE DESENVOLVIMENTO E DE INTERVENÇÃO PÚBLICA NO BRASIL RURAL SOB O GOVERNO TEMER E ALÉM
}

\author{
Arilson Favareto
}

\section{RESUMO}

A ascensão de Michel Temer à Presidência da República no Brasil após treze anos de governo do Partido dos Trabalhadores representa o fim de um ciclo nas formas de conceber o desenvolvimento e a ação pública nos espaços rurais do país. Além de apresentar evidências neste sentido, o artigo busca também mostrar a insuficiência das narrativas que hoje polarizam o debate público e a necessidade de uma nova agenda, mais consistente e coerente com os desafios postos pela trajetória brasileira recente e pelos novos marcos do capitalismo contemporâneo.

Palavras-chave: Desenvolvimento Rural; Políticas Públicas; Agricultura Familiar.

\section{CONCEPTIONS OF DEVELOPMENT AND PUBLIC ACTION IN RURAL BRAZIL UNDER TEMER GOVERNMENT AND BEYOND}

\section{ABSTRACT}

The rise of Michel Temer to the Presidency in Brazil after thirteen years of Workers Party governments represents the end of a cycle in the ways of conceiving the development and the public action for rural spaces in the Country. In addition to present evidences in this direction, the paper also seeks to show the insufficiency of the narratives that today polarize the public debate and the need for a new agenda, more coherent and consistent with the challenges posed by the recent Brazilian trajectory and the new milestones of contemporary capitalism.

Keywords: Rural Development, Public Policies, Family Farming. 


\section{INTRODUÇÃO ${ }^{1}$}

O governo Temer pode significar o fim de um ciclo nas formas de conceber o desenvolvimento e a intervenção pública nos espaços rurais do Brasil. O último ciclo teve iniciou nos anos 90 quando, numa coalizão que envolveu setores da burocracia governamental, reivindicações dos movimentos sociais rurais e parte da intelectualidade, foram forjadas algumas das principais políticas para a agricultura familiar que perduram até hoje - como o Programa de Fortalecimento da Agricultura Familiar (Pronaf), e a extensão de políticas sociais consagradas na Constituição de 1988 aos trabalhadores rurais - caso da política previdenciária. Nos anos 2000, nos marcos da ampliação das políticas sociais, agora como prioridade de Estado sob os governos Lula e Dilma, consolidou-se este modelo baseado na coexistência de dois setores, duas prioridades, duas estruturas institucionais: a agricultura patronal e a agricultura familiar, uma política de competitividade baseada na exportação de commodities e uma política de produção de alimentos com inclusão social, um Ministério da Agricultura e um Ministério do Desenvolvimento Agrário ${ }^{2}$. Símbolo do fim do ciclo é, tanto quanto o desmonte ou desidratação de programas importantes para a agricultura familiar e os trabalhadores sem-terra, a extinção do ministério que desde antes dos governos petistas coordenava as políticas para estes segmentos.

O que vem depois? Duas narrativas dominam o debate sobre qual agenda deve prevalecer. A primeira delas é a que vem sendo implantada desde a interrupção da sequência de treze anos de governos do Partido dos Trabalhadores e tem na chamada bancada ruralista sua principal voz. Trata-se daquilo que se poderia chamar de discurso "uma só agricultura". Para seus defensores, não faria mesmo sentido dois ministérios e a diferenciação de políticas para a agricultura empresarial e familiar. Nesta narrativa, o mundo rural se divide entre os que simplesmente "são" agricultores - independente da forma social de produção, se familiar ou patronal -, e aqueles que "estão" na condição de agricultores, os mais pobres, mas que não teriam condições de competir num futuro cada vez mais dominado pela tecnologia e pela seletividade competitiva, para os quais bastariam políticas sociais. Já a segunda narrativa tem como principais portadores movimentos sociais rurais e poderia ser chamada de discurso "volta Ministério do Desenvolvimento Agrário (MDA)", um correspondente no plano das políticas de desenvolvimento rural de "volta Lula". Nesta narrativa, por sua vez, a questão central se resume a reivindicar a retomada daquele pacote de políticas baseado na ampliação crescente de recursos para o Pronaf, na maior oferta de assistência técnica, na retomada de programas de compras públicas como o Programa de Aquisição de Alimentos (PAA) e o Programa Nacional de Alimentação Escolar (PNAE) com o mesmo peso de outrora, entre outras iniciativas que foram, sem dúvida, importantes para a melhoria de condições de vida da agricultura familiar na década passada.

O argumento central destas páginas, contudo, é que ambas as narrativas são insuficientes para garantir a expansão duradoura do bem-estar e a transição para um modelo de produção mais sustentável. Porque as duas aqui mencionadas já foram experimentadas e mostraram o que podem entregar, assim como seus limites. Mesmo aquilo que deu certo durante determinado período vinha demonstrando perda de fôlego em promover as transformações necessárias. Em vez de reeditá-las, o momento atual parece exigir um novo ciclo. Seja pelas insuficiências intrínsecas da primeira narrativa, que nada tem a dizer sobre a questão social ou ambiental nos

1 As páginas a seguir resultam de exposição realizada em três ocasiões: o VII Encontro da Rede de Estudos Rurais, o XI Fórum Internacional de Desenvolvimento Territorial, e a VIII Reunião de Trabalho do Fórum dos Gestores Estaduais Responsáveis pelas Políticas de Apoio à Agricultura Familiar no Nordeste e em Minas Gerais, todos realizados entre o segundo semestre de 2016 e o primeiro semestre de 2017. O caráter tópico e a linguagem adotada deve-se ao fato de tratar-se de notas de apoio à apresentação feita nestas ocasiões.

2 Grisa e Schneider (2014) apresentam uma visão pormenorizada da evolução das políticas e programas formulados no decorrer deste grande ciclo e suas diferentes etapas. 
termos postos pelo debate contemporâneo. Seja pelos limites conjunturais e mesmo estruturais que se impõem à segunda, nas quais estes temas têm destaque. Para sustentar esta ideia a exposição está organizada em mais quatro seções, além desta introdução e de uma breve conclusão: 1) O contexto internacional atual e suas repercussões para as possibilidades de desenvolvimento dos países latino-americanos; 2) O contexto brasileiro; 3) As narrativas em disputa no contexto de crise; 4) Oportunidades não aproveitadas para o desenvolvimento rural. Ao final uma breve conclusão apresenta nova pergunta, cuja resposta determinará a capacidade do país em inaugurar um novo ciclo de desenvolvimento e de políticas públicas para a expansão do bem-estar.

\section{O CONTEXTO INTERNACIONAL E SUAS CONSEQUÊNCIAS PARA A AMÉRICA LATINA}

Por que começar a exposição pelo contexto internacional? Entre outras possíveis razões, porque a crise brasileira contemporânea teve como um de seus detonadores a crise financeira internacional de 2007/2008. É verdade que nos anos imediatamente posteriores a esta data a economia brasileira ainda sustentou o crescimento que vinha sendo experimentado. Mas pouco a pouco a queda dos preços das commodities no mercado internacional acabou comprometendo o financiamento do modelo social-desenvolvimentista implementado durante os anos de governo do Partido dos Trabalhadores. Se até aquele momento vinha sendo possível expandir a renda dos mais pobres, aumentar a disponibilidade do crédito, investir na ampliação da infraestrutura, a virada para a segunda década deste século evidenciou os limites do arranjo anterior. Após 2012, marcadamente, a economia passou a dar sinais inequívocos de sérias dificuldades que viriam a redundar em estagnação, depois em recessão, acompanhada de crise política, tudo se intensificando ainda mais após $2014^{3}$. Justamente por isso alguns defensores do modelo da década passada argumentam que o problema não estaria na agenda social-desenvolvimentista, em si, e sim no contexto de crise internacional, que teria sido aproveitado pelas elites do país e redundado num golpe institucional que levou à deposição da Presidente Dilma Rousseff. Sob o ângulo programático, portanto, passada a crise estariam recompostas as condições que permitiram o êxito da primeira década do século XXI. Ocorre, porém, que a repetição daquelas condições é, antes de mais nada, pouco provável. E ainda que ocorra, dificilmente será suficiente para restabelecer a agenda dos anos 2000. Vale a pena ver as duas questões mais de perto.

A repetição do contexto de alta das commodities no mercado internacional pode até ser possível, mas segundo os especialistas não é o cenário mais provável. É certo que o crescimento mundial seguirá sendo impulsionado pelos países asiáticos, China à frente, isso significa certa demanda garantida para as commodities brasileiras. Entretanto, o ritmo do crescimento destes países não deve ser mais tão exuberante quanto aquele visto uma década atrás. Especificamente no caso chinês há uma reorientação no estilo de crescimento adotado. A expansão econômica na casa dos dois dígitos ao ano vem dando lugar a um planejamento governamental que trabalha com projeções mais modestas, ainda que vultuosas - não mais um crescimento acima de $10 \%$ ao ano, mas "apenas" algo em torno dos 7\%. Isto porque o crescimento muito acelerado, embora tenha reduzido significativamente a pobreza e permitido uma industrialização relativamente rápida, se fez acompanhar de forte desigualdade. E alta desigualdade entre grupos sociais pode abalar a coesão interna do regime, permitindo a emergência de conflitos e questionamentos. Para completar o quadro, a eleição de Donald Trump nos EUA se fez com a promessa de rever regras de comércio internacional, o que implicaria menor demanda pelos produtos chineses. Estes, exportando menos, também cresceriam menos, demandando menos ma-

3 Para uma análise mais consistente e detalhada do contexto político e econômico que envolveu a ação do Estado brasileiro no período ver especialmente Singer $(2012 ; 2015)$ e Bresser Pereira (2015). Uma apresentação dos contornos da agenda socialdesenvolvimentista pode ser encontrada em Mercadante (2010). 
térias primas de países latino-americanos. A consequência para o Brasil é que continuará havendo este estímulo de mercado, mas sem a mesma remuneração para as nossas commodities, como visto na década passada ${ }^{4}$. É o pior dos mundos: estímulos para especialização em bens primários, mas sem gerar a mesma riqueza de outrora.

O caráter não desejável da especialização das exportações brasileiras nas commodities, por sua vez, repousa em vários argumentos já bastante conhecidos, e que se pode mencionar de forma sumária: historicamente os bens primários apresentam uma tendência de queda em comparação aos preços relativos de bens manufaturados e de maior valor agregado, o que faz com que se tenha que exportar cada vez mais bens primários para importar a mesma quantidade de bens manufaturados com alta tecnologia incorporada, resultando em desequilíbrio permanente; não há qualquer controle local sobre os preços das commodities, que são determinados pelos mercados internacionais e pela concorrência com outros países produtores; há maior suscetibilidade a crises nos países compradores, repercutindo em restrições internas nos exportadores como o Brasil; e, finalmente, mas talvez mais importante, uma economia que se especializa na exportação de bens primários deixa de sofisticar, de organizar atividades de transformação e de suporte significativas, com tudo o que isso implica para a internalização das rendas e dos investimentos e para a emergência de outros setores sociais e de organizações representativas destes segmentos, algo fundamental para diminuir o peso político e econômico dos produtores de bens primários, como mostram os trabalhos de economistas como Paulo Gala (2017) ou Bresser Pereira (2015) e em consonância com as mais recentes contribuições da economia do desenvolvimento, como os livros de Acemoglu e Robinson (2014) ou de Douglass North et al (2009), para os quais a desconcentração da riqueza e do poder estão na base de ciclos duradouros de crescimento econômico com expansão do bem estar justamente, porque impedem a captura dos incentivos do Estado e da alocação do fundo público. As consequências indesejadas da especialização em exportação de commodities envolve, portanto, aspectos produtivos e aspectos relativos à estrutura das classes sociais. Envolve não só a forma de inserção internacional, mas também as condições de construção de uma economia sólida, complexa e resiliente. Por tudo isso a especialização na exportação de commodities não é desejável, mesmo com os atrativos de se obter rendas de curto prazo. E no longo prazo caberia ainda levantar mais uma interrogação, relativa aos pesados investimentos chineses na África. As condições climáticas permitem a produção de soja e carnes naquele continente com custos potencialmente inferiores àqueles que envolvem as exportações brasileiras, por exemplo com o transporte. Seria razoável ou prudente imaginar que os chineses seguirão dependentes do Brasil como grande fornecedor nos mesmos moldes atuais por décadas a fio?

$\mathrm{O}$ contexto internacional ainda traz outros agravantes. $\mathrm{O}$ espaço da inserção internacional que o Brasil buscou no século passado, via industrialização, desde Getúlio Vargas, depois com Juscelino Kubitschek, posteriormente com os militares, e que seria buscado também sob Lula, vem sendo ocupado justamente pelos países asiáticos, destacadamente chineses e coreanos. As economias americana e europeia se voltam ao setor terciário avançado, alguns setores de alta tecnologia, e à financeirização de suas economias. Os asiáticos ocupam o espaço da produção de bens de consumo, por exemplo com a indústria automobilística ou eletroeletrônica além de outros manufaturados. E os países latino-americanos passam por um processo de reprimarização de suas pautas de exportações, apesar de todo aquele esforço desenvolvimentista empreendido nos últimos 80 ou 90 anos. Trata-se, por aqui, de uma reprimarização das exportações acompanhada de uma terceirização da economia doméstica, gerando empregos e renda sobretudo no setor de comércio e serviços. Porém, não um setor de comércio e serviços avançado, ligado aos setores produtivos industriais, como na Europa e EUA. Não é um setor de ser-

4 Sobre a evolução recente da experiência chinesa e suas injunções ver os trabalhos de Fabiano Escher et al. (2015). 
viços que se cria após o amadurecimento da industrialização, ao menos em boa parte do país. Mas sim um setor terciário movimentado por serviços pouco intensivos em tecnologias, que não se fez anteceder ou acompanhar de ampla industrialização. Um processo que, justamente por esta razão, o economista Dani Rodrik (2015) chamou de desindustrialização precoce. Ora, diante do recuo da indústria nas exportações e da queda do preço das commodities, como continuar financiando a política social e a expansão dos investimentos em equipamentos públicos e em infraestrutura que marcou o auge do progressismo latino-americano? Este setor terciário, embora intensivo em mão de obra, não se sustenta sozinho justamente porque, em vez de ser impulsionado pelos outros setores produtivos (agricultura e indústria), é puxado sobretudo pela expansão do gasto social do Estado, agora abalado pela crise fiscal decorrente da nova condição de preços das commodities.

Outros elementos do contexto internacional, estes de mais longo prazo, também trazem desafios para os países latino-americanos, em geral, e para o Brasil em particular. No que diz respeito à dimensão ambiental, uma das grandes apostas de tendências tecnológicas futuras é a transição para uma economia de baixo carbono. Para que não pareça mera promessa futura e abstrata, basta lembrar que a China, país que vem puxando o crescimento mundial recente, tem investido pesadamente em mudanças na sua matriz energética, com grandes investimentos em energia solar, e tem adquirido empresas internacionais de biotecnologia. É um exemplo pontual, mas representativo de um movimento geral que implica na substituição crescente de fontes fósseis de energia e materiais em direção a uma nova base, possivelmente mais diversificada, em escala planetária. Num tal quadro, a demanda por materiais apoiados na tríade biodiversidade, biomassa e bioenergia - os três “b” de que falava Ignacy Sachs (2007) décadas atrás nos seus trabalhos sobre as Estratégias de transição para o século XXI - tende a aumentar. Isto, somado à demanda por produtos agropecuários e à projetada escassez de água, fazem da base de recursos naturais dos países latino-americanos um objeto de investimento absolutamente atrativo. Não é por outra razão que os chineses estão adquirindo significativas porções de terras no continente africano e ampliando seus investimentos na América Latina, ou que fundos de pensão norte-americanos e canadenses estão também investindo em áreas que permitam o controle de recursos naturais no Brasil, num processo que a literatura chama de land grabbing, algo que vem sendo objeto de crescente atenção entre pesquisadores internacionais e brasileiros, entre os quais cabe mencionar os estudos de Sauer e Leite (2012). Isto é, já está em curso um processo de estrangeirização dos recursos naturais que ameaça o que poderia ser a base material de uma promissora nova porta de entrada para o Brasil na divisão internacional da economia - uma matriz produtiva de alta tecnologia baseada em novas formas de uso dos recursos naturais, para além das commodities.

Ainda nas questões de caráter mais estrutural do contexto internacional é crescente a preocupação nos países mais ricos do mundo sobre como reequacionar sua coesão social interna. Como mostram os estudos de Thomas Piketty (2014), no livro O capital no século XXI, após mais de meio século de redução de desigualdades alcançada com o chamado Estado de bem-estar social europeu, os últimos 20 ou 30 anos foram palco de uma rápida reversão desses ganhos, com os patamares de desigualdade retornando rapidamente ao ponto em que estavam no período anterior às grandes guerras mundiais. Isto decorre principalmente das novas condições do capitalismo internacional: com a revolução da microeletrônica se produz cada vez mais com menos gente trabalhando e o setor financeiro tornou-se o polo dinâmico da acumulação; um setor que, por sua vez, emprega pouco e contribui pouco com a produção de bens materiais voltados ao bem-estar. Não é mais tão necessário ao capital expandir os mercados consumidores, pois sua reprodução está garantida com apenas uma parte da população mundial consumindo ou com os ganhos no mercado financeiro. O resultado é uma exclusão estrutural, que se 
manifesta nos altos índices de desemprego - na Espanha quase um quarto da população e quase 50\% dos jovens estão sem trabalho, por exemplo - e na dificuldade em seguir financiando as políticas sociais que garantiram a redução da desigualdade e o bem-estar dos chamados trinta anos gloriosos ou dourados do capitalismo mundial no período pós-guerra. É esta fissura no contrato social o que explica fenômenos como a saída do Reino Unido da União Europeia (o chamado Brexit), a eleição de Trump, a ascensão de discursos xenófobos e contra imigrantes de partidos nacionalistas conservadores.

Por tudo isso, o mesmo Ignacy Sachs mencionado acima dizia que o mundo contemporâneo apresenta temas e questões de natureza bastante diferentes daqueles experimentados no decorrer do século XX (Sachs, 2009). Justamente por isso, dizia ele, as grandes narrativas ou projetos de organização social que representaram as principais utopias do século XX não se sustentam mais. Em suas palavras, estamos sentados sobre os escombros de três modelos de organização social que a sociedade criou nos últimos cem anos. A experiência do socialismo real, se bem logrou elevar o patamar de bem-estar das populações dos países onde foi aplicado, revelou-se um modelo pouco afeito à democracia política e à pluralidade. Além disso, embora tenha promovido saltos de produtividade e competitividade econômica fantásticos, não se mostrou capaz de sustentar este crescimento em longo prazo. No outro extremo, a experiência do liberalismo tampouco oferece boas respostas para as questões ambiental, social e mesmo para o crescimento econômico de longo prazo. Onde foi implantado o liberalismo logrou conviver com regimes democráticos e muitas vezes permitiu algum equilíbrio de contas públicas, mas na maior parte dos casos contribuiu para aumentar a desigualdade, em vez de diminuí-la, pouco fez pela ampliação do bem-estar social, e não levou a ciclos econômicos virtuosos duradouros. Após alguns anos seus custos sociais aparecem e as populações clamam por mudanças. Por fim, a experiência da social democracia talvez seja a que conseguiu melhor equilibrar aspectos dos dois modelos anteriores: resultou num conjunto de políticas aplicadas em regimes democráticos, que ensejaram um crescimento duradouro e uma ampliação do bem-estar. Contudo, a própria concretização de seus êxitos solapou as bases de sua manutenção. As inovações tecnológicas tornaram o emprego relativamente descartável e a exclusão estrutural erodiu os mecanismos que permitiam a expansão e a sustentação deste modelo de organização da economia e da vida política. O que deu relativamente certo durante trinta anos, deixou de funcionar.

Se quiserem dar conta dos desafios do século XXI as sociedades talvez tenham que buscar a constituição de novas narrativas e modelos de organização social condizentes com o novo contexto. Há embriões de novas narrativas. Não é mero acaso que, quando surgem os sinais claros de crise daquelas três narrativas tradicionais é justamente quando ocorre a ascensão da retórica do desenvolvimento sustentável. Recentemente o acordo internacional em torno dos Objetivos do Desenvolvimento Sustentável (ONU, 2015) representam uma tentativa de ampliar os Objetivos do Desenvolvimento do Milênio, voltados prioritariamente ao combate à pobreza mundial, introduzindo variáveis relativas à dimensão ambiental, às desigualdades e ao estilo de crescimento econômico. Ainda é muito cedo para afirmar que se trata de uma nova narrativa com alcance similar às anteriores, sobretudo em função do seu caráter genérico e da ausência de formas de governança consistentes e coerentes com os avanços discursivos (Veiga, 2017). Mas no mínimo os ODS têm o mérito de pôr sobre a mesa uma nova agenda de temas, mesmo que sem a resposta sobre como equacioná-los. Neste quadro, o que dizer sobre o Brasil?

\section{O CONTEXTO BRASILEIRO}

O contexto brasileiro é marcado por uma brutal inversão de expectativas. Nos meados da década passada a revista The Economist publicava uma capa com uma imagem da estátua do 
Cristo Redentor subindo aos céus como um foguete, acompanhada da manchete "O Brasil decola”. A economia crescia 4\% ao ano em média, a pobreza diminuía de forma inegável. As reservas de petróleo do pré-sal, recém descobertas, prometiam um futuro mais rico. A situação era de virtual pleno emprego. O país era escolhido para sediar os maiores eventos esportivos internacionais, ampliando sua visibilidade externa. Virada a década Lula e seu partido passam a ser alvo de grandes manifestações de rua e de processos judiciais que ameaçam torna-lo inelegível. A mesma revista publica nova capa, com a mesma estátua do Cristo Redentor, mas agora em pane, voando em parafuso, com a manchete "Eles estragaram tudo?". A economia patina, inflação e contas públicas extrapolam as metas estabelecidas, a redução da pobreza diminui de ritmo, o desemprego cresce, setores que apoiavam o governo agora sabotam iniciativas voltadas a tentar corrigir rumos. Se concretiza a crise institucional que levou à deposição da ex-presidente Dilma Roussef, assumindo em seu lugar Michel Temer, que também se tornaria alvo de acusações de corrupção. Um ano depois, momento em que estas páginas são escritas, a economia patina, os indicadores sociais não melhoram, a crise de legitimidade atinge os três poderes da República. Se não é possível afirmar quando e como a crise terá seu fim, é possível perguntar qual é o balanço que se pode fazer da década passada e que desafios estão postos para engendrar um novo ciclo. A resposta não é simples, mas alguns elementos podem ser postos sobre a mesa.

O primeiro elemento é o fato de que, inegavelmente, os anos 2000-2010 foram uma década vitoriosa, marcada por crescimento econômico, forte redução da pobreza, relativa redução das desigualdades, como já foi mencionado acima. A sequência de mapas a seguir mostra isso claramente. Mostra também que esta melhoria vinha desde antes, é verdade, mas se intensificou muito nos anos 2000. Especificamente no que diz respeito à manifestação territorial destes indicadores, os mapas mostram ainda que a melhoria foi praticamente generalizada em todo o território nacional, em quase todos os indicadores. Uma exceção cabe justamente para o índice de desigualdade de renda: enquanto os outros indicadores melhoraram em praticamente todo o território nacional, especialmente nas porções Norte e Nordeste há uma significativa quantidade de municípios onde, embora a pobreza tenha diminuído e a renda aumentado, a desigualdade permaneceu estável ou mesmo aumentou, na contramão do que ocorreu no conjunto do país. E como mostram os dados compilados por Medeiros (2015) e Morgan (2017), esta melhoria se observa quando considerada a renda do trabalho. Se, para além disso, for considerada a riqueza das famílias, a desigualdade aumentou em termos agregados no país no mesmo período.

Mapas 1 a 3 - Índice de Desenvolvimento Humano dos Municípios Brasileiros (1991, 2000, 2010)

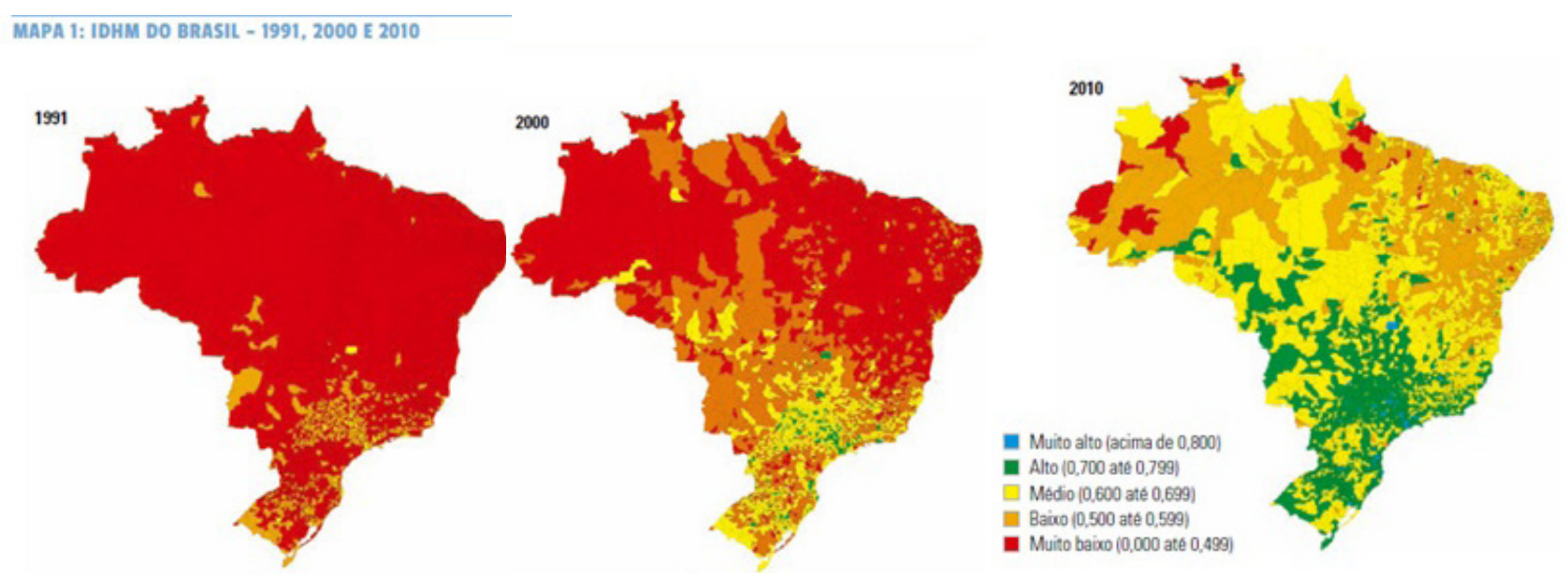

Reproduzido de: PNUD (2016). 
MAPAS 4 E 5 - VARIAÇÃO DOS INDICADORES DE POBREZA E DESIGUALDADE NOS MUNICÍPIOS BRASILEIROS (2000-2010)
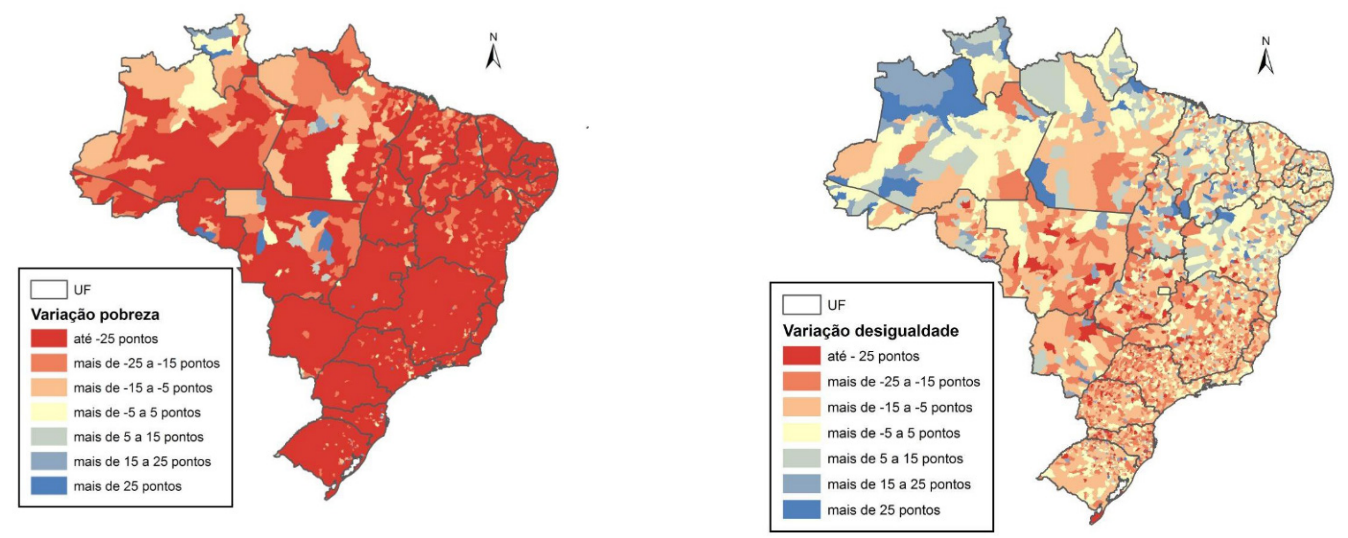

Reproduzido de: Favareto et al. (2014) com base em dados do IBGE.

Um segundo aspecto importante a destacar também nestes mapas é que, mesmo com todo o progresso experimentado nestes vários indicadores, a desigualdade Norte-Sul no país permanece. Ou, mais que isso, o que se verificou na década passada, com uma economia puxada sobretudo pelo setor terciário e pela agropecuária, foi a consolidação de certos perfis regionais. O mapa a seguir mostra justamente a ocorrência de três padrões predominantes, quando se comparam os níveis de renda, de bem-estar, e de desigualdade. Numa grande mancha que envolve a maior parte dos municípios do Norte e do Nordeste, mesmo com todos os avanços ainda predominam os níveis mais baixos de renda e de bem-estar. Na porção central do Brasil, predominam municípios com baixos níveis de bem-estar, apesar da alta renda e de variável desigualdade. Na poção Sul-Sudeste do Brasil, há uma mescla de dois tipos de municípios: aqueles onde se combina bons indicadores de renda e bem-estar com baixa desigualdade, mas um número igualmente expressivo onde há bons indicadores de renda e bem-estar, mas alta desigualdade. Isto é, no Brasil Central o grande desafio é converter a alta renda gerada em maior bem -estar; no Sul-Sudeste o problema maior é enfrentar a desigualdade que predomina em muitos municípios, e no Norte-Nordeste a questão ainda é melhorar todas as dimensões, diminuindo o hiato que contrasta estas regiões com o Sul-Sudeste. O Brasil não experimentou, portanto, um estilo de desenvolvimento nos anos recentes, e sim vários. Ou um, que se manifesta espacialmente em várias expressões territoriais, como mostra o mapa.

\section{MaPa 6 - Perfis de DesenVOlVIMENTO dos MUNicípios BRASILEIROS A PARTIR DO CONTRASTE ENTRE} RENDA, PRODUÇÃO E BEM-ESTAR (2010)

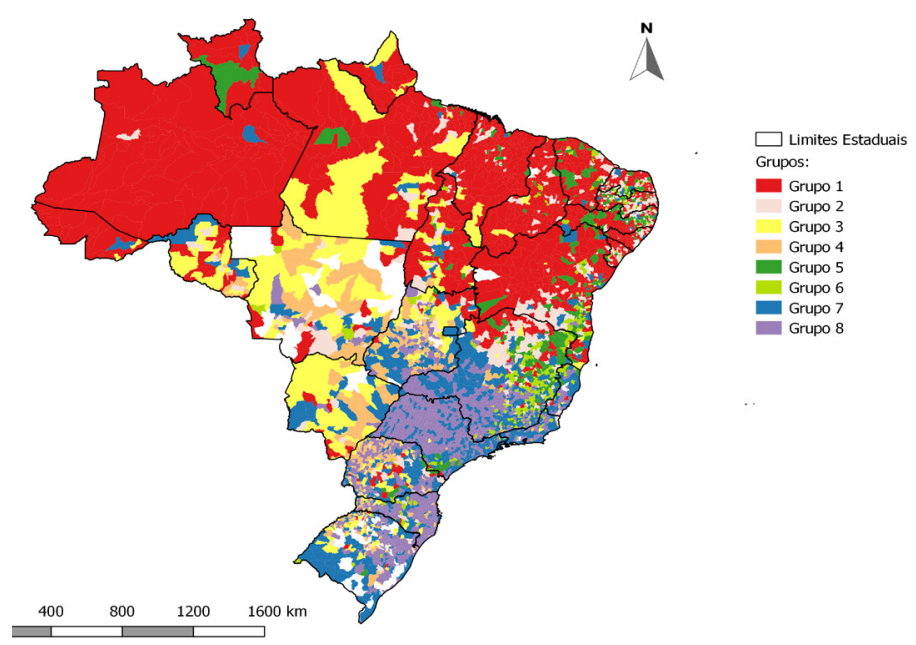




\begin{tabular}{|c|c|c|c|}
\hline & BEM-ESTAR & RENDA & DeSIGUALDADE \\
\hline Grupo 1 & Baixo & baixo & baixo \\
\hline Grupo 2 & Baixo & baixo & alto \\
\hline Grupo 3 & Baixo & alto & baixo \\
\hline Grupo 4 & Baixo & alto & alto \\
\hline Grupo 5 & Alto & baixo & baixo \\
\hline Grupo 6 & Alto & baixo & baixo \\
\hline Grupo 7 & Alto & alto & alto \\
\hline Grupo 8 & Alto & alto & \\
\hline
\end{tabular}

Reproduzido de: Favareto et al. (2014) com base nos dados de IBGE e outras fontes nacionais.

O terceiro aspecto que marca nossa trajetória recente é o estancamento do ciclo recente. Para esta exposição, basta mencionar dois indicadores que mostram como já na virada da década os indicadores de desempenho do Brasil vinham arrefecendo. Desde 2012 a redução da pobreza interrompeu a trajetória virtuosa que vinha experimentando, de início com estabilização e em seguida com ligeiro aumento do número de pobres. Isto se deve tanto ao fato de que agora trata-se do chamado núcleo duro da pobreza, mais difícil de ser revertido, como também ao contexto de maior restrição fiscal que atingiu a capacidade do Estado em continuar com o mesmo tom na sua política social. Com o aprofundamento da crise, dados mais recentes mostram que, somente em 2015, 4,1 milhão de pessoas entraram ou voltaram para a condição de pobreza (IPEA/PNUD/FJP, 2017). Número que deve ter crescido ainda mais em 2016. Da mesma forma, o crescimento econômico perdeu ímpeto ao longo do primeiro mandato de Dilma Rousseff, se transformou em seguida em estagnação, e, mais recentemente, já sob Temer, em recessão. Estes elementos estão na base da corrosão da legitimidade dos governos petistas e formaram o terreno propício para que as denúncias de corrupção, que haviam tido início ainda no primeiro mandato de Lula, agora encontrassem eco em setores mais amplos da população. O que se quer dizer com isso é que não foi a crise política quem detonou a crise econômica. Ocorreu uma situação na qual a degradação dos indicadores econômicos minou a autoridade e o respaldo do governo, transformando-se em crise sistêmica, na qual os aspectos políticos, econômicos e mesmo morais passaram a se influenciar mutuamente e num sentido negativo. É óbvio que houve um movimento coordenado de setores conservadores e que resultou no agravamento da crise e na deposição de Dilma Rousseff. Mas é preciso olhar para a perda de fôlego do modelo que abriu fissuras para que conflitos de interesses no seio da sociedade brasileira tivessem os desdobramentos hoje conhecidos. O resultado deste tipo de constatação é que não bastaria, portanto, estancar a crise política para que a dimensão econômica voltasse a apresentar bom desempenho. Ao contrário, seria preciso agora, para superar a crise, atacar simultaneamente os dois domínios. Algo que, até o momento, não se conseguiu.

O quarto aspecto a destacar é o caráter absolutamente decisivo da política social brasileira nesta melhoria de indicadores. A tabela a seguir traz indícios desta magnitude. As aposentadorias e pensões representaram em valores de 2014 aproximadamente 340 bilhões de reais anuais, beneficiando diretamente 31 milhões de pessoas e mais de 100 milhões indiretamente. Seria preciso quase 100 do Programa de Aquisição de Alimentos (PAA) e do Programa Nacional de Alimentação Escolar (PNAE) somados, ou 20 do Pronaf para chegar a número similar. Se considerados somente os recursos das aposentadorias rurais seria preciso o dobro dos chamados programas produtivos para alcançar o mesmo patamar de investimentos. Quando consideramos que a economia de boa parte dos pequenos municípios do país se apoia em empresas e 
empregos sobretudo de comércio e serviços em grande medida impulsionados por este tipo de recursos, as transferências públicas, fica claro que não é só a renda de muitas famílias, mas também a economia de regiões inteiras que dependem da política social brasileira. É por esta razão que a alteração das regras de investimentos sociais, como a recente alteração constitucional que limita a expansão do gasto público ou como a reforma da previdência, são medidas com impacto avassalador, não só nos indicadores sociais, mas também econômicos do Brasil interiorano. Os índices de desemprego atuais, mais elevados no Nordeste, são claro reflexo disto.

Tabela 1 - Dimensão das POlíticas PÚBlicas PaRa o DESENVOLVIMENTO RURAL E O COMbATE À pobreza - Brasil, Norte e Nordeste. Dados mais recentes para cada programa. Benefícios APRESENTADOS EM MILHARES E VALORES EM MILHÕES DE REAIS

\begin{tabular}{|c|c|c|c|c|c|c|}
\hline \multirow[b]{2}{*}{ Políticas - Programas } & \multicolumn{2}{|c|}{ BRASIL } & \multicolumn{2}{|c|}{ Nordeste } & \multicolumn{2}{|c|}{ NorTE } \\
\hline & $\begin{array}{c}\text { Benefícios } \\
\text { ou } \\
\text { Contratos }\end{array}$ & Valor & $\begin{array}{c}\text { Benefícios } \\
\text { ou } \\
\text { contratos }\end{array}$ & Valor & $\begin{array}{l}\text { Benefícios } \\
\text { ou } \\
\text { contratos }\end{array}$ & valor \\
\hline \multicolumn{7}{|c|}{ PREVIDÊNCIA (2012 - DEZ 2012) } \\
\hline aposentadorias. pensões e auxílios & 25.176 & 278.778 & 6.561 & 57.288 & 1.074 & 9.459 \\
\hline aposentadorias e pensões rurais & 8.482 & 60.945 & 4.112 & 28.707 & 712 & 4.831 \\
\hline BPC (2014 - dez 2014) & 4.130 & 35.141 & 1.500 & 12.741 & 414 & 3.520 \\
\hline \multicolumn{7}{|c|}{ Bolsa FAMÍlia (2014 - JuNHO 2015} \\
\hline Total & 13.717 & 27.186 & 6.915 & 14.120 & 1.646 & 5.595 \\
\hline Rural & 3.744 & 8.422 & 2.455 & 5.595 & 522 & 1.365 \\
\hline \multicolumn{7}{|c|}{ Pronaf (2014) } \\
\hline Custeio & 615 & 10.152 & 51 & 461 & 15.741 & 267 \\
\hline Investimento & 1.224 & 14.596 & 773 & 2.994 & 87.623 & 1.783 \\
\hline PAA (2013) & 96 & 467 & & 37 & & 180 \\
\hline PNAE (2013) & & 3.693 & & 1.138 & & 253 \\
\hline agricultura familiar & & 2.474 & & 660 & & 152 \\
\hline Garantia Safra (2013/14) & 909 & 773 & 868 & 738 & & \\
\hline Cisternas (2013) & 77 & & & & 74 & \\
\hline total $2003-2013$ & 1.049 & & & & 966 & \\
\hline Bolsa Verde (2014) & 37 & 11 & 5 & 2 & 29 & 9 \\
\hline Auxílio Defeso (2014) & 861 & 2.355 & 437 & 1.195 & 293 & 802 \\
\hline dez 2014 & 168 & & & & & \\
\hline Subtotal (rurais/agrícolas + BPC) & & 97.840 & & 39.194 & & 8.587 \\
\hline Total & & 338.010 & & 77.972 & & 18.347 \\
\hline
\end{tabular}

Reproduzido de: Silveira et al. (2016), com base em Registros Administrativos do Incra, MPS, MDS, MDA, MMA, MEC, Portal da Transparência

Este caráter decisivo da política social para as regiões rurais também pode ser observado na análise dos mapas 7 a 9. Neles se pode ver: como os municípios onde predomina a participação industrial no valor adicionado da economia são relativamente restritos; como a economia do Brasil central é fortemente vinculada à agropecuária; e como a economia dos municípios do Semiárido e da Amazônia, destacadamente, está apoiada no setor de comércio e serviços. A presença do setor terciário também é forte na porção meridional do país, mas ali este setor apresenta mais vínculos com atividades industriais, resultando em empregos de maior remuneração e de melhor qualidade. Na porção setentrional do Brasil, como foi dito, o setor de comércio e serviços é fortemente dependente da massa de recursos injetada a partir das transferências públicas de vários tipos, já que a produção agropecuária e industrial é frágil. 


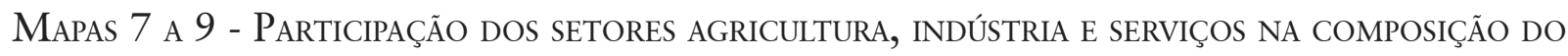

VALOR Adicionado dOS MUNicí́tios BRASILEIROS - 2010
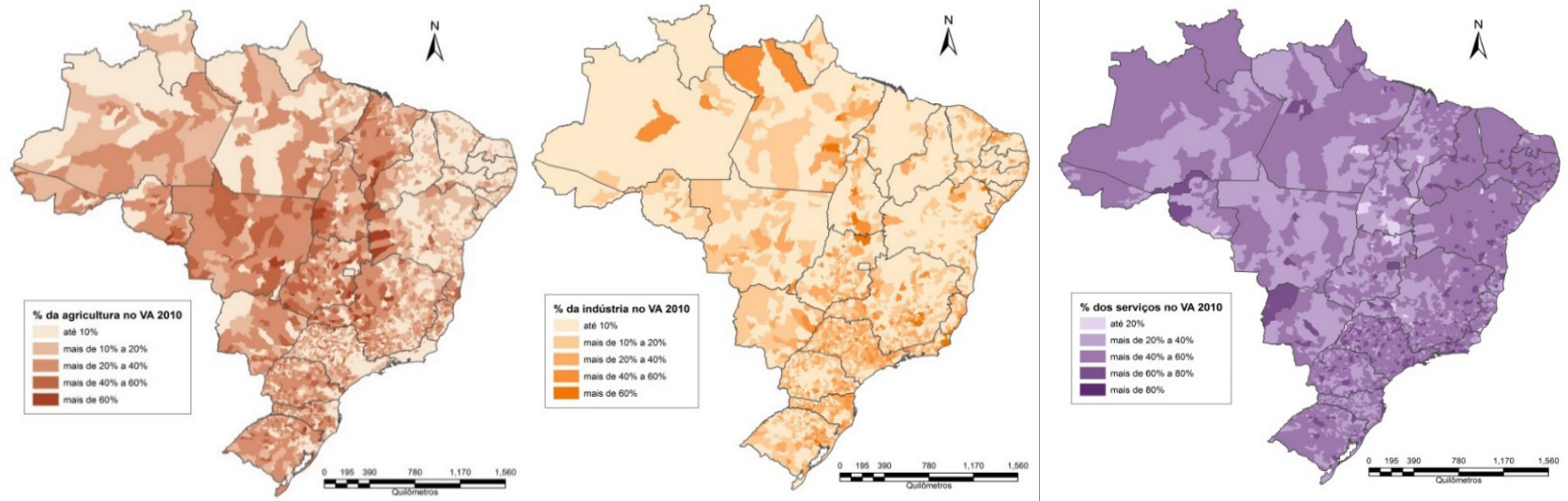

Reproduzido de: Favareto et al. (2014) com base nos dados do IBGE e IPEA.

De tudo o que foi dito, quais são as implicações para o futuro do Brasil rural? A principal talvez seja o fato de que, apesar do contexto favorável da década passada, o país ainda não tem uma estratégia de desenvolvimento rural. Esse era justamente o título de um texto publicado por José Eli da Veiga no começo dos anos 2000 (Veiga et al. 2001). Passados 15 anos desde então, a afirmação permanece verdadeira. Na melhor hipótese o Brasil teve duas estratégias, ou uma esquizofrenia. De um lado, apostou pesadamente na primarização de suas economias, via exportação de commodities, reforçando o que Acemoglu e Robinson (2014) chamam de instituições políticas e econômicas extrativas. De outro, organizou um importante feixe de políticas baseadas na expansão das liberdades e dos direitos dos mais pobres e em instituições inclusivas. Este segundo vetor de políticas compensava, em parte, a concentração e a exclusão estrutural geradas pela dependência das commodities. Mas fazia isso de forma dependente das receitas extras geradas com o ciclo de alta dos preços destas commodities no mercado internacional, condição que deixou de existir.

Os defensores desta opção argumentam que não era possível adotar caminho diferente, dada a correlação de forças favorável aos setores exportadores de commodities e outros segmentos menos importantes economicamente do agro, mas detentores de poder político - por exemplo, os setores mais atrasados e que, junto com os exportadores, se fazem representar por meio da chamada Bancada Ruralista no Congresso Nacional, com forte incidência sobre a ação do Estado. Isto pode ser verdade. Mas também é correto destacar que não se pôs no horizonte a perspectiva de mudanças a médio prazo neste tipo de arranjo. Ao contrário, a perspectiva se ateve a manter a ampla coalizão que se formou em torno do primeiro mandato de Lula, e que reunia praticamente todos os segmentos e interesses da sociedade brasileira. Basta lembrar seu primeiro ministério, formado por representantes do setor financeiro (Henrique Meirelles, egresso do Banco de Boston, foi nomeado presidente do Banco Central) do setor industrial (com Luis A. Furlan, egresso da Sadia, no Ministério da Indústria), do setor agropecuário (com Roberto Rodrigues no Ministério da Agricultura, egresso da Sociedade Rural Brasileira), mas também dos movimentos sociais (com Marina Silva no Ministério do Meio Ambiente, ligada ao movimento ambientalista; ou com vários nomes ligados ao movimento sindical, em diferentes ministérios da área social). Nas três eleições seguintes ganhas pelo PT se buscou repetir esta coalizão ampla. Coalizões de forças sociais implicam em combinar interesses contraditórios, o que é diferente da ideia clássica de conciliação de classes, nas quais se apagam os conflitos e se enfatizam as convergências. O problema não está, assim, como apontam alguns, na coexistência de classes com interesses contraditórios no arranjo de forças que deu suporte aos 
governos petistas, o que sempre será necessário num regime democrático. O problema é que não se pactuou quem seriam os setores, dentre as classes e grupos sociais, que teriam que perder ou ganhar menos para que transformações estruturais viessem a ocorrer. Não por outra razão Bresser Pereira (2015) utiliza a expressão “o pacto que não houve” para caracterizar o período. Outro argumento também visto com frequência é que a convivência entre os dois setores do agro brasileiro não seria conflitiva, pois ambos estariam, inclusive espacialmente, ocupando posições distintas: a agricultura familiar no Norte, Nordeste e partes do Sul e Sudeste, e a agricultura patronal concentrada na porção Central do Brasil e em manchas nas demais regiões. Sob um argumento ou outro, criou-se a ilusão de que seria possível a coexistência duradoura ou mesmo a complementaridade dos chamados dois modelos na agropecuária brasileira, o familiar e o patronal, cada um no seu quadrado. Um incluiria as pessoas, outro geraria as divisas para que o Brasil pudesse financiar o social-desenvolvimentismo e, com ele, a prioridade à redução da pobreza e à inclusão social, o fortalecimento da agricultura familiar.

No entanto, o que se observa é que os quadrados não são tão separados assim. Para começar, aquilo que equivocadamente se chama de agronegócio comporta na verdade três segmentos: há, é claro, aquela porção da agricultura patronal que corresponde à imagem pública do "agro é tech", com seus altos índices de produtividade e geração de riquezas - ainda que com altos custos ambientais e com enorme poupança de trabalho (portanto, gerando impactos ambientais e aumentando a desigualdade); mas há também aquele segmento que segue atuando como a velha agricultura patrimonialista, que se apresenta como agronegócio mas nada produz, usa a terra como reserva de valor e forma de dominação, e só se reproduz graças a perdão de dívidas ou a formas espúrias de competitividade como a grilagem e outras práticas; e, por fim, há uma parte da agricultura familiar que é agronegócio, como aqueles que produzem carnes de pequenos animais e outros setores importantes das cadeias produtivas agroalimentares. Chamar tudo isso de agronegócio é legitimar o discurso dos setores dominantes de que há "uma só agricultura". Esta imagem engana a sociedade brasileira e garante o respaldo da opinião pública. Quando, na verdade, um destes segmentos, o patrimonialista, é parasitário: pouco ou nada produz, gera gasto público, gera degradação ambiental, gera desigualdades. Outro é, claro, produtivo, e será preciso conviver com ele, mas os custos sociais e ambientais inerentes a este modelo precisa ser internalizado e compensado pelo próprio setor; isto é, a economia brasileira hoje precisa dele, mas não necessariamente sobre as mesmas bases. E o terceiro segmento mostra que nem tudo o que gera alta produção é a grande propriedade. Parte da imagem da moderna agricultura brasileira deve-se, também, a esta agricultura familiar que pode apresentar os mesmos índices de produtividade da patronal competitiva, porém com menos custos para o Estado. Num excesso de flexibilidade conceitual este terceiro setor tem sido chamado por alguns de "agronecocinho", porque o padrão tecnológico seria o mesmo da grande empresa. Uma denominação equivocada, porque o resultado social desta forma de produção não é o mesmo da agricultura patronal de grande escala. Não é só uma diferença de tamanho, como sugere o sufixo diminutivo. Há ali uma diferença qualitativa na distribuição social da riqueza gerada, apesar das críticas que, aí sim, se deve fazer aos efeitos deletérios do padrão tecnológico adotado.

Outro aspecto que evidencia a dificuldade em pensar na complementaridade binária dos dois modelos de produção no agro brasileiro está no fato de que os demais setores da agricultura familiar, sobretudo os mais pobres, foram, obviamente, beneficiados com a grande expansão de recursos e com a diversificação dos instrumentos de apoio. Mas eles são ainda fortemente dependentes do gasto social e da política de expansão de direitos que vigorou na ação do Estado na década passada. Ora, não é mero acaso que a vanguarda do atraso na pauta política do Brasil atual tem justamente na Bancada Ruralista, ao lado da Bancada Evangélica, um aríete 
fundamental, o que resulta não só em mudanças na legislação que afeta povos indígenas, áreas de conservação, quilombolas entre outros; este são os setores que contribuíram decisivamente para viabilizar a alteração constitucional que limita os gastos públicos por vinte anos, que sustenta a agenda mais ampla de reformas com retirada de direitos e daí por diante. Em outras palavras, há um poder econômico que se traduz em poder político e cujos efeitos se fazem sentir em toda a agenda pública brasileira e afetando diretamente as populações mais vulneráveis no capo e na cidade, justamente porque o que está em jogo são os contornos da ação do Estado e a alocação do fundo público. São os velhos temas do patrimonialismo e da especialização primária que nos acompanham ao longo da formação do Brasil. Não é só uma questão de modelos de produção na agropecuária. É uma questão que diz respeito ao capitalismo brasileiro, sua base produtiva, a constituição das classes e grupos sociais. Em suma, a ideia da complementaridade entre os dois setores se implode diante da diversidade interna de cada um dos dois grandes grupos, e sofre um curto circuito quando se percebe que a base de reprodução do velho patrimonialismo não pode conviver, senão como exceção, com uma ação do Estado voltada à inclusão dos mais pobres. Com isso não se quer dizer, obviamente, que seria possível, num programa voltado a um novo ciclo, abrir mão da existência da agricultura patronal. O que seria preciso, isso sim, é diminuir o hiato entre as duas estratégias, de forma que elas não fossem tão antagônicas, não representassem uma esquizofrenia. Significaria admitir as contradições e os conflitos, mas operar com eles, em vez de promover somente sua justaposição como se os dois setores ocupassem espaços diferentes e complementares.

Por fim, é preciso reconhecer que a partir da crise de 2007 houve uma tentativa de recompor o modelo brasileiro, diminuindo a dependência externa num contexto de crise internacional. Foi o que se tentou fazer com a chamada Nova Matriz Econômica: reforçar o mercado interno e a indústria nacional, diminuindo taxas de juros e ampliando o crédito e outros incentivos como isenção de impostos e controle de tarifas. O problema é que o custo desta opção se revelou demasiado alto, e os resultados não surgiram como esperado. Uma das fragilidades desta tentativa de inflexão é que, sob o ângulo político, a chamada Nova Matriz envolvia reformar a coalizão de forças sociais que deu sustentação aos governos do PT e que foi, desde então, se esfacelando pouco a pouco. Outra fragilidade é que, se já é difícil reformar esta coalizão de forças sociais num período comum, num contexto de restrições como aquele marcado pela forte crise internacional é algo ainda mais complicado. Não era mais possível continuar com os ganhos sem que algum dos setores sociais que estavam na coalizão de apoio dos governos petistas passasse a perder. Ao longo dos anos 2000 quem mais ganhou foram os mais pobres. Além disso, ganhou bastante o topo da pirâmide social. As classes médias, se por um lado não perderam, ganharam menos do que os outros. Gradativamente este setor foi vendo a alta elite se distanciar, à sua frente, e os trabalhadores se aproximando, pelo retrovisor. A melhoria do poder aquisitivo dos mais pobres encareceu serviços e impactou simbolicamente estas classes médias tradicionais, cuja distinção se perdia com a chegada do que se chamou no período, um tanto equivocadamente, de novas classes médias. Este foi o primeiro setor a abandonar o barco e a passar à oposição frontal ao governo. O segundo segmento foi o setor rentista da sociedade, cujos interesses foram abalados pela tentativa de redução acentuada dos juros no período. O terceiro setor foi o industrial, que inicialmente pedia controle de tarifas de energia e de combustíveis e isenção de impostos, depois atacou o governo acusando-o de ser perdulário por adotar tais medidas. Finalmente, setores da classe trabalhadora também deixaram de apoiar o governo em função da elevação da inflação e do desemprego, que cresciam no período já que o investimento privado não respondia aos estímulos governamentais. A espiral negativa eliminou as possibilidades de saída da crise no curto prazo. Vendeu-se nova ilusão: de que a troca de governo bastaria. 


\section{A DISPUTA DE NARRATIVAS}

Vinda a troca de governo, que narrativas passaram a dominar o debate público? Duas agendas polarizam a cena atualmente. Ambas sem respostas convincentes para se chegar a saídas duradouras da crise. Ambas voltadas ao passado, reproduzindo receitas já aplicadas nos anos 90 , de um lado, ou nos anos 2000 , de outro. E isso vale para as narrativas sobre a crise, em geral, e sobre o Brasil rural, em particular.

No plano geral, a polarização envolve as retóricas liberal e desenvolvimentista. Para a narrativa liberal, a raiz da crise está no descompasso entre o aumento das despesas públicas e a capacidade de financiamento do Estado. Minimizada a possibilidade do financiamento externo, com a queda das commodities, o único caminho seria ajustar gastos e receitas. Não pontualmente, e sim estruturalmente ${ }^{5}$. Economistas alinhados com este pensamento usam o argumento de que a trajetória de descompasso entre despesas e receitas seria estrutural e o mal original estaria na Constituição de 1988, que teria reconhecido direitos em demasia, para além do que o país poderia custear. Daí a ofensiva sobre dispositivos constitucionais: a emenda que congelou os gastos públicos, a reforma previdenciária e trabalhista, entre outros. Esta narrativa acerta em apontar que há um problema de financiamento no desenvolvimento brasileiro. Mas erra no diagnóstico da causa do problema e na sua mensuração. Erra na causa porque o problema não é a Constituição reconhecer direitos em demasia, e sim o déficit de direitos da sociedade brasileira e sua forma de financiamento. E erra na mensuração porque não é verdade que $o$ aumento dos gastos descolado do aumento do produto bruto em níveis perigosos é constante. Houve certo descolamento nos anos recentes, é certo, mas isto não vale na mesma medida para todo o período desde a Constituição de 1988. Esta narrativa engendra a mesma agenda de austeridade dos anos 90, mas ainda mais radical, porque propõe um retorno ao patamar de compromisso social anterior à Constituição de 1988.

A outra narrativa, a desenvolvimentista, em especial a vertente social-desenvolvimentista dentro deste campo, peca justamente por minimizar a existência de um problema de financiamento. Com exceção para autores como Barbosa (2015), parte dos portadores deste discurso, sobretudo na esfera política, colocam toda a ênfase no contexto internacional ou na ação das elites para explicar a crise. Sua aposta principal é que o pior da crise já teria passado pois a inflação está voltando à meta pactuada, agora que os preços já absorveram a alta da gasolina e da energia após o fim da política de preços controlados, e também em função da retração econômica geral que conteve a demanda. Aposta também que a crise internacional já estaria menos turbulenta e que o futuro trataria de reconstituir as condições que permitiram o êxito da década passada. Alguns ajustes são sugeridos, mas o cerne do programa consiste na reedição do modelo já experimentado. Outra exceção neste campo político é o documento lançado em 2016 por um grupo de economistas ligados ao PT, com um programa de emergência para sair da crise, no qual o tema do financiamento adquire um outro tratamento. Há, ali, a ideia de uma reforma tributária que coloque na mobilização de riquezas hoje concentradas em certos segmentos muito abastados da sociedade brasileira a carga necessária para viabilizar a retomada do investimento social e em infraestrutura, o que poderia ser complementado também com um uso seletivo das reservas cambiais do país. Mas não se sabe se este esboço de atualização da narrativa desenvolvimentista encontraria portadores políticos em condições de angariar o apoio de forças sociais influentes, armando uma coalizão capaz de sustentar tal programa. Ou se, ao contrário, a tentativa de volta ao governo faria o PT e seu candidato acenarem novamente com a

5 Esta perspectiva está claramente apontada no documento do PMDB (2014). Uma ponte para o futuro, que serviu como uma espécie de programa compromisso para a ascensão de Temer à chefia do Estado. Uma justificativa teórica pode ser encontrada nos textos de economistas como Pessoa, Lisboa e Mansueto (2015). 
tentativa de reedição da grande coalizão que teve sucesso quinze anos atrás. Não basta ideias, é preciso portadores sociais destas ideias constituídos e com expressão e força para sustenta-las. Hoje esta é uma pergunta a espera de uma resposta: qual seria o arranjo de forças sociais capaz de dar forma a uma agenda consistente de saída da crise? As elites parecem indispostas a adotar reformas de que o país precisa. E os setores populares, por sua vez, não tiveram força para impedir a volta de uma agenda conservadora e parecem ser insuficientes para sustentar, sozinhos, esta agenda de reformas que possa gerar um novo e duradouro ciclo de crescimento com distribuição de renda e expansão do bem-estar.

No plano dos espaços rurais também há uma polarização de narrativas. De um lado, encontramos o que se poderia chamar de hipótese convergente, porque sugere que não deve haver distinções e divergências substantivas entre formas sociais de produção na agricultura. Nas palavras de uma grande liderança do setor empresarial da agropecuária, existiria "uma só agricultura". Há os que podem ser considerados agricultores, cujos interesses seriam convergentes, e outros que estão nesta condição apenas temporariamente, sem condições de se manter como agricultores no futuro, frente à concorrência e à competição crescente. Para o grupo dos que são vistos como "verdadeiros agricultores”, deveriam ser reservadas as políticas agrícolas, de tecnologia, de crédito. Para o grupo dos que não serão agricultores, apenas estão nesta condição antes de serem varridos pela concorrência, bastariam as políticas sociais compensatórias. Adeptos desta hipótese encabeçaram um documento assinado pela Frente Nacional da Agropecuária, nome oficial da Bancada Ruralista, no momento imediato ao afastamento definitivo de Dilma Rousseff da presidência. Nele se reivindicam aspectos voltados a melhorar as condições de competitividade para o agronegócio nacional como aperfeiçoamento da infraestrutura e do ambiente institucional, busca agressiva de mercados internacionais, agilização da pesquisa agrícola e revisão da legislação trabalhista, além de aprimoramento das condições de financiamento e seguro. No que diz respeito aos temas ambientais, o documento aposta na chamada agricultura de precisão e melhor informação como forma de melhorar a eficiência no uso de recursos naturais. Quanto à arquitetura institucional, o documento pedia a unificação das políticas para a agricultura familiar e patronal, sob o argumento de que todos são agricultores, exceção feita para os assentamentos rurais que demandariam atenção destacada, o que não ocorreu. Pedia ainda a criação de um ministério unificado do rural, algo que também não ocorreu, já que parte das políticas do antigo Ministério do Desenvolvimento Agrário foram direcionadas para o Ministério do Desenvolvimento Social, numa disputa entre forças políticas que apoiaram a deposição da presidente eleita. Pedia ainda alterações no pacote de políticas do antigo MDA, sem precisar exatamente o que deveria ser mudado. E associava o problema da agricultura do Nordeste, onde se concentram os agricultores mais fragilizados, a uma questão social e ao fortalecimento do cooperativismo. Embora se possa criticar este conjunto de medidas por apostar todas as fichas no binômio tecnologia e mercados como a pedra de toque para a solução dos problemas do Brasil rural e por esvaziar a fundamental distinção entre duas formas específicas de produção na agricultura, a familiar e a patronal, não há dúvida de que ele representa certa visão de futuro para a agricultura brasileira. Uma visão que consiste em intensificar a opção dos anos anteriores e que transformou o Brasil num líder mundial em produção agropecuária, mas com graves problemas socioambientais. O ponto central é que, nesta visão de futuro, tudo se resume ao aumento da produção e da produtividade. E há evidências de sobra para a insuficiência do produtivismo nos marcos do capitalismo contemporâneo, em geral, e brasileiro, em particular.

A outra narrativa sobre o rural brasileiro é empunhada sobretudo pelos movimentos sociais rurais. Ela poderia ser resumida na defesa do pacote de políticas do antigo MDA. A reivindicação das organizações e o posicionamento de alguns intelectuais e gestores de políticas públicas comprometidos com o modelo anterior não tem apontado para uma nova geração, mas 
sim para a resistência e defesa de manutenção de programas até então existentes, algo bastante compreensível e talvez correto frente ao grau de descontinuidade dos investimentos que vinham sendo feitos e do arranjo institucional que foi sendo gradativamente montado desde o governo Fernando Henrique Cardoso, com a criação do MDA e do Pronaf, e ampliado significativamente nos anos Lula e Dilma. Se é compreensível e correto, por um lado, é preciso reconhecer, por outro, que se trata de narrativa insuficiente para fazer frente aos problemas que já vinham sendo experimentados naquele cardápio de programas. Exemplo destes limites é a concentração dos recursos aplicados via Pronaf no segmento de agricultores mais capitalizados e nas regiões Sudeste e Sul do país. Junto disso, são muitas as críticas ao modelo de produção favorecido com esta modalidade de crédito. Há ainda dificuldades reconhecidas na operacionalização dos programas de compras públicas. É verdade que há vozes dissonantes, por exemplo entre movimentos e lideranças da agroecologia. Mas mesmo os movimentos sociais apenas muito timidamente opinaram sobre o conjunto da política para o setor. Enquanto houve expansão do atendimento das demandas específicas - mais uma vez, repita-se, legítimas e com resultados inquestionáveis - pouco se questionou o modelo geral.

Importante: não se está dizendo aqui que as duas narrativas se equivalem, pois, uma delas está mais voltada a tentar corrigir desigualdades históricas e a promover mudanças qualitativa no modelo agropecuário. O que se argumenta é que nenhuma das duas narrativas dá conta dos desafios postos à construção de uma nova etapa, de um novo ciclo, de uma nova estratégia de desenvolvimento para o Brasil rural.

Neste embate, o que tem prevalecido? As primeiras medidas do governo Temer, obviamente, sinalizam a adesão à agenda proposta pela Bancada Ruralista. Porém, menos pelos seus aspectos modernizantes e como defendido por alguns dos intelectuais a ela ligados, mas principalmente no sentido de favorecer velhas formas patrimonialistas e arcaicas de competitividade espúria. Matéria de Maria Cristina Fernandes, publicada no jornal Valor, em maio de 2017, elenca lista de medidas exemplares de tal movimento. É o caso da Medida Provisória editada por Temer logo no primeiro mês de governo renegociando dívidas que resultou em redução de até 95\% do montante para produtores rurais pendentes com instituições públicas. É o caso da nomeação de um representante da Frente Parlamentar da Agropecuária para o Ministério da Justiça, que comanda a Funai, com quem há vários conflitos explosivos envolvendo produtores rurais. Entre as negociações em andamento está a proposta da Frente Parlamentar da Agropecuária de reduzir a contribuição previdenciária para $1,2 \%$ da receita agrícola e o perdão para as dívidas com o Funrural. Na reforma trabalhista, líderes do setor propuseram a adoção da flexibilização da legislação para permitir até 18 dias de trabalho ininterruptos, a possibilidade de que até $45 \%$ do pagamento possa ser feito em troca de alimento e moradia, o que na prática reinstitui modalidades de servidão de um século atrás. Para completar, há a flexibilização da legislação para permitir a compra de terras por estrangeiros, mudanças na legislação sobre demarcação de terras indígenas e unidades de conservação. Sem falar no congelamento ou desmonte de programas específicos para a agricultura familiar. Como se vê, por trás do aparente discurso modernizante, a agenda do setor patronal continua se destacando pelo mais velho e escancarado patrimonialismo.

\section{OPORTUNIDADES}

Keynes certa vez usou uma frase que se tornou célebre - seria preciso pensar no curto e médio prazos, pois no longo prazo, estaremos todos mortos. A realidade brasileira talvez convide a inverter a afirmação - com a gravidade da crise, no curto prazo estamos todos mortos. Por isso é importante pensar a médio prazo, ainda que numa perspectiva que possa começar 
a ser experimentada desde já. Na seção inicial se argumentou que o Brasil precisa buscar uma nova forma de inserção internacional, com correspondente reorientação de sua base produtiva nacional. Na segunda seção se cogitou que a crise atual é estrutural e que seria preciso pensar num novo ciclo com especial atenção às regiões interioranas do Brasil, destacadamente Nordeste e Amazônia. Na terceira seção viu-se que as narrativas disponíveis apenas propõem a reedição do passado. Nesta quarta seção o objetivo é apresentar brevemente três campos de oportunidades que poderiam ser mobilizados em tal direção, mas que, no entanto, não habitam as narrativas em curso. Talvez seja nestas oportunidades que se encontram alguns dos caminhos para uma nova agenda capaz de reconstituir a importância do Brasil rural e interiorano numa estratégia de desenvolvimento mais inovadora.

Uma primeira oportunidade reside na interiorização dos fluxos demográficos e econômicos que o país experimenta desde os anos 90. Hoje há 300 cidades no país com mais de cem mil habitantes. As metrópoles deixaram de ser o principal polo de atração e crescimento populacional. Somente o rural distante ou isolado ainda apresenta sinais de esvaziamento. Há mesmo um grande número de pequenos municípios onde a população cresce mais rapidamente. Esta é uma realidade completamente distinta daquela vista uma geração atrás, marcada pelo êxodo rural-urbano e por uma expectativa de que caminhávamos para um esvaziamento das regiões rurais. Veiga (2002) já chamava a atenção para isso no seu livro Cidades imaginárias, de quinze anos atrás. Mas continuamos ignorando o enorme potencial que esta nova rede de cidades comporta para uma estratégia de desenvolvimento. Com esta nova configuração também há uma interiorização de investimentos, públicos e privados, como indústrias, redes de supermercados, entre outros ramos e setores. As novas cidades médias do interior do Brasil são importantes bases pois representam mercados, disponibilidade de equipamentos públicos, enfim, centros dinâmicos com os quais é preciso pensar formas de vínculo das zonas rurais de seu entorno. Este aspecto, no entanto, vem sendo solenemente ignorado nas estratégias de desenvolvimento rural no Brasil. Uma política de desenvolvimento territorial, por exemplo, deveria se apoiar predominantemente nestes novos fluxos e em como criar possibilidades de que as famílias rurais possam aproveitá-los da melhor forma.

Uma segunda oportunidade é dada pela fantástica interiorização das redes de educação, ciência e tecnologia, predominantemente ao longo dos últimos dez anos. Não só há uma sólida rede de pesquisa agropecuária, formada pelas unidades da Embrapa, mas houve também na década passada uma forte expansão do ensino superior e da rede de educação profissional, científica e tecnológica. Foram dezenas de universidades ou campus universitários criados, predominantemente no interior do Brasil. Foram centenas de escolas e institutos federais criados também predominantemente no interior do Brasil. Entretanto, estas três redes praticamente não dialogam entre si. Pior, não dialogam com a imensa rede de ensino fundamental e médio. O desafio posto às regiões rurais vai além da produção de subsistência ou do abastecimento do mercado interno de alimentos. Vai além também da sistematização de conhecimentos tradicionais agroecológicos. É preciso mobilizar a ciência e a tecnologia para um tipo de produção agropecuária que possa reconciliar sociedade e natureza, por meio da produção de novos conhecimentos. Práticas como a chamada agricultura regenerativa sinalizam a possibilidade de um novo paradigma onde a produção não esteja em conflito aberto e insanável com a conservação ecossistêmica. Mais além, é preciso utilizar esta expertise do mundo da educação e da ciência para pensar o próprio futuro destas regiões rurais. E, por outro lado, é preciso irrigar o mundo da ciência e da tecnologia com os problemas e também com os conhecimentos produzidos fora dos muros das universidades ou dos limites dos laboratórios. É preciso reconectar estes dois mundos, de forma que possam se fertilizar mutuamente. Hoje estes temas estão praticamente ausentes da agenda científica e tecnológica. E é algo que não se limita à simples sistema- 
tização de conhecimentos tradicionais como advogam alguns movimentos. Construir um novo ambiente educacional para os jovens rurais seria uma oportunidade fantástica para evitar a repetição de velhas fórmulas e para projetar um novo horizonte.

Finalmente, uma terceira grande oportunidade diz respeito às novas demandas por utilização de recursos naturais. Hoje o Brasil se notabiliza por transformar seu estoque de recursos biogenéticos em pastagens e lavouras. Tudo indica que a Humanidade caminha para uma grande transição, substituindo materiais fósseis por recursos biogenéticos, como tem apontado em seus textos Abramovay $(2010 ; 2012)$. O Brasil vai na contramão desta tendência e aposta suas fichas no petróleo, em setores como a indústria automobilística, ou em um modelo de expansão da agropecuária que resulta em erosão da biodiversidade. Ora, as áreas prioritárias para a conservação e as fontes naturais de energia como a eólica e a solar estão justamente na Amazônia e no Nordeste do Brasil. Uma nova estratégia de desenvolvimento rural deveria fortalecer os usos destes vetores, sem ter que abrir mão da produção de alimentos ou produtos de exportação. E nada disso impede a continuidade dos investimentos na agricultura familiar. Significa apenas a ampliação de oportunidades e a busca por novos vetores de inserção econômica, reduzindo a dependência de políticas sociais e de práticas espúrias ainda muito presente nas estratégias empresariais do setor agropecuário.

\section{CONCLUSÃO: A GRANDE PERGUNTA}

A reprimarização, a produção de manufaturas típicas do capitalismo industrial, ou mesmo a financeirização, caminhos que hoje guiam as formas de inserção de países e regiões nos circuitos econômicos, não são caminhos capazes de levar à convergência entre crescimento duradouro, redução da pobreza e da desigualdade, e conservação ambiental. Para isso parece ser necessário um novo estilo de desenvolvimento. E, nele, será preciso conferir lugar igualmente novo e de destaque ao Brasil rural e interiorano e às formas de uso dos recursos naturais do país. Os escombros das duas grandes narrativas sobre o desenvolvimento brasileiro nas décadas recentes, o liberalismo e o social-desenvolvimentismo, não trazem este tipo de respostas. Tampouco o fazem as narrativas específicas sobre o desenvolvimento rural que nada mais são do que desdobramento setorial das anteriormente mencionadas. Claro que o ciclo que parece estar no fim pode ser prolongado. A história não é linear, tampouco previsível. O futuro bem pode trazer a insistência em reeditar alternativas já experimentadas. Apenas não se deve esperar delas resultado diferente do que já apresentaram, tanto em seus sucessos como em seus limites. Os processos de transformação mais amplos são cada vez mais intensos e não há razões para imaginar que soluções moldadas num contexto que em grande medida já não existe possam seguir sendo eficientes. A questão central será saber qual agenda de prioridades, políticas e programas pode materializar este novo ciclo e qual é a coalizão de forças sociais que pode sustentar tal agenda. Hoje este tipo de agenda e de coalizão não parecem estar em vias de formação. É preciso atualizar as utopias e as formas de interpretação sobre o capitalismo brasileiro, suas bases materiais, suas formas de inserção internacional. O contexto é severo, mas embriões de oportunidades, de uma nova narrativa, de novos portadores e de novas práticas surgem inevitavelmente. Transformar este arquipélago de inovações e seus agentes em uma plataforma capaz de oferecer horizonte novo e promissor é algo que pode ser buscado, desde que se rejeite a ditadura do curto prazo. Contribuir com este esforço foi o intuito principal destas notas. 


\section{REFERÊNCIAS}

ABRAMOVAY, R. Desenvolvimento sustentável - qual estratégia para o Brasil? Revista Novos Estudos CEBRAP, n. 87, p. 97-113, 2010.

ABRAMOVAY, R. Muito além da economia verde. São Paulo: Abril, 2012

ACEMOGLU, D.; ROBINSON, J. Por que as nações fracassam. Rio de Janeiro: Campus, 2014.

BARBOSA, N. O desafio macroeconômico de 2015-2018. Revista de Economia Política, v. 35, n. 3, p. 403-425, jul./set. 2015.

BRESSER PEREIRA, L. C. A construção política do Brasil. São Paulo. Editora 34, 2015.

ESCHER, F. et al. Bilateral Relations and Development Trajectories of Brazil and China: BRICS'Agrarian Issues at the Centre of the Contemporary 'Double Movement'. Working Paper, n. 7. Bicas - BRICS Initiative for Critical Agrarian Studies, 2015.

FAVARETO et al. A dimensão territorial do desenvolvimento brasileiro recente (2000-2010). Documentos de Trabajo. Santiago do Chile: Rimisp, 2014.

FERNANDES, M. C. O mote da produtividade: do cambão à fralda. Jornal Valor, maio de 2017.

GALA, P. Complexidade econômica: uma nova perspectiva para entender a antiga questão da riqueza das nações. São Paulo: Contraponto, 2016.

GRISA, C.; SCHNEIDER, S. Três gerações de políticas públicas para a agricultura familiar e formas de interação entre sociedade e estado no Brasil. Revista de Economia e Sociologia Rural, Brasília, v. 52, n. 1. 2014.

MEDEIROS, M. et al. O topo da distribuição de renda no Brasil: primeiras estimativas com dados tributários e comparação com pesquisas domiciliares (2006-2012). Dados, Rio de Janeiro, v. 58, n. 1, jan./ mar. 2015

MERCADANTE, A. As bases do novo desenvolvimentismo: análise do governo Lula. Tese de Doutorado. Campinas: Unicamp, 2010.

MORGAN, M. Extreme and persistent inequality: new evidence for Brazil combining national accounts, surveys and fiscal data (2001-2015). Working Paper Series, n. 12, 2017.

NORTH, D. et al. Violence and social orders: a conceptual framework for interpreting recorded human history. Cambridge University Press, 2009.

ONU. Transformando nosso mundo: a Agenda 2030 para o desenvolvimento sustentável. Nova York: United Nations, 2005.

PIKETTY, T. O capital no século XXI. São Paulo: Intrínseca, 2014.

PESSOA, S.; LISBOA, M.; ALMEIDA, M. Ajuste inevitável: desequilíbrio da economia brasileira é estrutural e exige correções mais duras e profundas. Folha de São Paulo, 19 jul. 2015.

PMDB. Uma ponte para o futuro. Disponível em: <www.pmdb.org >. Acesso em: 19 jul. 2014.

PNUD/IPEA/Fundação João Pinheiro. Relatório Radar IDH-M. Disponível em: < http://www.atlasbrasil.org.br/2013/data/rawData/RadarIDHM_VERSAO_Final_6.pdf.>. Acesso em: 13 jun. 2017.

RODRIK, D. Premature deindustrialization in the developing world. Disponível em: <http://rodrik. typepad.com/dani_rodriks_weblog/2015/02/premature-deindustrialization-in-the-developing-world. html>. Acesso em $\overline{13}$ set. 2015.

SACHS, I. Rumo a ecossocioeconomia: teoria e prática do desenvolvimento. São Paulo: Cortez, 2007.

SACHS, I. A terceira margem do rio: em busca do ecodesenvolvimento. São Paulo: Companhia das Letras, 2009. 
SAUER, S.; LEITE, S. P. Expansão agrícola, preços e apropriação de terra por estrangeiros no Brasil. Revista de Economia e Sociologia Rural, Brasília, v. 50, n 3, p. 503-524, jul./set. 2016.

SILVEIRA, F. G. et al. Políticas públicas para o desenvolvimento rural e de combate à pobreza no campo. Brasília: IPC-IG/PNUD, 2016.

SINGER, A. Os sentidos do lulismo. São Paulo: Companhia das Letras, 2012.

SINGER, A. Cutucando onças com varas curtas - o ensaio desenvolvimentista no primeiro mandato de Dilma Rousseff. Novos Estudos CEBRAP, 2015.

VEIGA, J. E. et al. O Brasil rural precisa de uma estratégia de desenvolvimento. Textos para Discussão n. 1. Brasília: NEAD, 2001.

VEIGA, J. E. Cidades imaginárias: o Brasil é menos urbano do que se calcula. Campinas: Associados, 2002.

VEIGA, J. E. A primeira utopia do Antropoceno. Revista Ambiente e Sociedade. v. 20, n. 2, p. 227-246, 2017. 